\title{
Video Resumes and \\ Job Search Outcomes: \\ Evidence from a
}

\section{Field Experiment}

CHARLES BELLEMARE

MARION GOUSSÉ

GUY LACROIX

STEEVE MARCHAND 


\section{$\checkmark$ CIRANO Knowledge into action}

Center for Interuniversity Research and Analysis on Organizations

The purpose of the Working Papers is to disseminate the results of research conducted by CIRANO research members in order to solicit exchanges and comments. These reports are written in the style of scientific publications. The ideas and opinions expressed in these documents are solely those of the authors.

Les cahiers de la série scientifique visent à rendre accessibles les résultats des recherches effectuées par des chercheurs membres du CIRANO afin de susciter échanges et commentaires. Ces cahiers sont rédigés dans le style des publications scientifiques et n'engagent que leurs auteurs.

CIRANO is a private non-profit organization incorporated under the Quebec Companies Act. Its infrastructure and research activities are funded through fees paid by member organizations, an infrastructure grant from the government of Quebec, and grants and research mandates obtained by its research teams.

Le CIRANO est un organisme sans but lucratif constitué en vertu de la Loi des compagnies du Québec. Le financement de son infrastructure et de ses activités de recherche provient des cotisations de ses organisations-membres, d'une subvention d'infrastructure du gouvernement du Québec, de même que des subventions et mandats obtenus par ses équipes de recherche.

\section{CIRANO Partners - Les partenaires du CIRANO}

Corporate Partners - Partenaires corporatifs

Autorité des marchés financiers

Bank of Canada

Bell Canada

BMO Financial Group

Business Development Bank of Canada

Caisse de dépôt et placement du Québec

Desjardins Group

Énergir

Hydro-Québec

Innovation, Science and Economic Development Canada

Intact Financial Corporation

Manulife Canada

Ministère de l'Économie, de la Science et de l'Innovation

Ministère des finances du Québec

National Bank of Canada

Power Corporation of Canada

PSP Investments

Rio Tinto

Ville de Montréal

Academic Partners - Partenaires universitaires

Concordia University

École de technologie supérieure

École nationale d'administration publique

HEC Montréal

McGill University

National Institute for Scientific Research

Polytechnique Montréal

Université de Montréal

Université de Sherbrooke

Université du Québec

Université du Québec à Montréal

Université Laval

CIRANO collaborates with many centers and university research chairs; list available on its website. Le CIRANO collabore avec de nombreux centres et chaires de recherche universitaires dont on peut consulter la liste sur son site web.

(C) August 2020. Charles Bellemare, Marion Goussé, Guy Lacroix, Steeve Marchand. All rights reserved. Tous droits réservés. Short sections may be quoted without explicit permission, if full credit, including (c) notice, is given to the source. Reproduction partielle permise avec citation du document source, incluant la notice (c)

The observations and viewpoints expressed in this publication are the sole responsibility of the authors; they do not necessarily represent the positions of CIRANO or its partners. Les idées et les opinions émises dans cette publication sont sous l'unique responsabilité des auteurs et ne représentent pas nécessairement les positions du CIRANO ou de ses partenaires. 


\title{
Video Resumes and Job Search Outcomes: Evidence from a Field Experiment
}

\author{
Charles Bellemare *, Marion Goussé ${ }^{*}$, Guy Lacroix *, Steeve Marchand $\$$
}

\begin{abstract}
Résumé
We evaluate the efficiency of video resumes using a large scale field experiment. We randomly sent applications to 2021 private firms posting vacancies across the province of Québec (Canada). A subset of these applications included a link inviting firms to view a video resume. We find that video resumes increase callback rates by more than 10 percentage points. We also evaluate the service for individuals with acute visible disabilities (wheelchair users). Although our results support the presence of discrimination in the labor market, we show that they benefit from video resumes as much as applicants without a disability.
\end{abstract}

Keywords/Mots-clés: Video Resume, Job Search, Disabilities, Discrimination

JEL Codes/Codes JEL: J71, J68

* Département d'économique, Université Laval, Québec, Canada and CIRANO. Corresponding author: Charles.Bellemare@ecn.ulaval.ca. Funding from the Canadian Instituts of Health Research and the Social Sciences and Humanities Research Coucil (number 890-2016-3048) is acknowledged. We thank Laure Sébrier and Manuel Paradis for their support. Declarations of interest: none.

† Département d'économique, Université Laval, Québec, Canada. Marion.Gousse@ecn.ulaval.ca. Declarations of interest: none.

¥ Département d'économique, Université Laval, Québec, Canada and CIRANO. Guy.Lacroix@ecn.ulaval.ca. Declarations of interest: none.

§ Département d'économique, Université Laval, Québec, Canada. Steeve.Marchand@berkeley.edu. Declarations of interest: none. 


\section{Introduction}

Job search is a complex and costly endeavor. Job seekers must choose a search strategy that includes how much effort to exert, which channel to use, the type of job to prospect, the location, etc., all the while ignoring whether job offer arrival rates depend on their effort. Fortunately, the advent of the digital economy has lowered search cost and presumably increased the quality of matches between firms and workers (Goldfarb and Tucker, 2019). Indeed, recent evidence suggests that unemployed workers who use online platforms exit unemployment faster than those who do not (Kuhn and Mansour, 2014).

Online platforms have undoubtedly reduced search frictions. Yet, online interactions between job seekers and firms are essentially limited to the exchange of traditional resumes. ${ }^{1}$ In this paper, we go one step further and investigate the impact of using video resumes on callback rates for low to middle-skill jobs. Video resumes are becoming increasingly popular and can be hosted directly on internet platforms or can be referenced through a hyperlink when uploading a resume to a potential employer. Video resumes allow job seekers to showcase their abilities beyond the capabilities of traditional paper resumes and allow prospective employers to see and hear applicants, and get a feel for how applicants present themselves.

Our goal is to verify the extent to which presenting oneself more intimately through a video resume may be beneficial or detrimental to applicants. We conducted two large-scale field experiments in the Province of Québec (Canada) between 2016 and 2019. In our main experiment (the "video experiment"), we sent as many as $2,021 \mathrm{CVs}$ between September 2018 and April 2019, part of which explicitly provided a link to a video resume. We targeted secretary-receptionist positions advertised on standard job search engines (Indeed.ca, emploiquebec.gouv.qc.ca). A professional actress was hired to personify a potential candidate in the video resumes. We recorded detailed viewing

\footnotetext{
${ }^{1}$ In the context of international hiring, recent evidence suggests that outsourcing agencies play an important role in helping inexperienced workers using online services land a job early in their career (Stanton and Thomas, 2015).
} 
activities from potential employers (number of views, duration, rewind/forward, etc.) as well as callbacks either by email or via a voice message.

The impact of a promotional video is potentially heterogeneous and may depend on individual characteristics. For instance, it may have a deleterious effect if it reveals otherwise concealed information that is not to the liking of an employer (race, gender, obesity, disability, etc.). To this end, a subset of our applications disclosed a disability requiring the use of a wheelchair. This was achieved by filming the actress sitting in a wheelchair. The disability was mentioned explicitly in the cover letter in cases where the resumes that did not mention a video. The videos used both a narrow and a wide frame and only the latter showed the wheelchair. Half of them switched from a narrow to a wide frame after 13 seconds while the other half switched after 51 seconds. Disclosing the disability at two different moments may be used to investigate whether giving an applicant more time to inform an employer of one's skills has any impact on potential discrimination.

In order to detect statistical differences in the effect of video resumes for individuals with and without a disability, and late versus early disclosure, we used the results from a prior experiment (the "benchmark experiment") to perform a power analysis before designing our video experiment. In this benchmark experiment, we sent 1,477 traditional resumes between May 2016 and April 2017. These applications did not include a video resume, but roughly half mentioned a disability requiring the use of a wheelchair. We could therefore measure baseline callback rates of non-disabled and disabled individuals and conduct a power analysis prior to launching our video experiment in order to assess the distribution and number of application types that needed to be sent.

Our results show that the video resumes increase the callback rates by 10 percentage points for able bodied and disabled workers alike. The latter are nevertheless found to be discriminated against as they are much less likely to be convened to a formal interview, even once we control for workplace accessibility and after we correct for the Heckman (1998) critique using the Neumark (2012) approach. Furthermore, we find 
that the callback rate of able bodied workers is positively correlated with viewing time. Unfortunately, we find the exact opposite for disabled workers. In addition, we find no evidence that disclosing the disability later than sooner attenuates discriminatory attitudes.

The contribution of our paper is twofold. First, we evaluate the effectiveness of the video resume which is a low-cost and easily replicable tool and show that it increases significantly the callback rates of unemployed individuals. This has important policy implications. Indeed, the research of the last thirty years has shown that governmentsponsored training and job assistance programs have had limited success in helping disadvantaged individuals find employment in the U.S. and in Europe (Crépon and Van Den Berg, 2016; Card et al., 2018), but also in Canada (Lacroix et al., 2011). To the extent video resumes are beneficial to these individuals, they may prove to be a costeffective alternative to standard government programs. The second contribution of our paper is to provide additional empirical evidence to the literature that focuses on measuring discrimination facing persons with disabilities through fictitious randomized applications (Ravaud et al., 1992; Ameri et al., 2018; Kauer and Deuchert, 2017; Baert, 2016). The major caveat of this literature is the omission of the possible confounding effects of workplace accessibility. Yet, recent papers by Thapar et al. (2004) for Greater Boston area and Evcil (2009) for Istanbul show that as much as $80 \%$ of public buildings are not accessible by wheelchair. Differences in callback rates between able-bodied and disabled individuals are thus perhaps largely explained by accessibility issues. Hence, controlling for workplace accessibility as we do in this paper is of primary importance to obtain unbiased measures of the effects of video resumes for this population.

The evidence presented in the paper contributes to the literature on the extent to which private information should be disclosed when searching for a job. It has been previously found that disclosing information about gender (Neumark et al., 1996), age (Lahey, 2008), address (Bunel et al., 2016), ethnic origin (Bertrand and Mullainathan, 2004), immigration status (Oreopoulos, 2011) or even including a picture (Rooth, 2009; Patacchini et al., 2015) had detrimental effects on callback rates in some circumstances. 
Strategically limiting available information may increase interview opportunities for minority groups. ${ }^{2}$ Yet, to the extent video resumes are becoming ever more popular, concealing information may be worse than being too explicit. As found by Behaghel et al. (2015), anonymous resumes decreased callback rates for some minority groups. Besides, concealing information is becoming difficult in a digital economy. Indeed, Acquisti and Fong (2020) showed that a significant proportion of employers search online through social media sites for personal information on candidates. In contrast, our results are in line with recent evidence according to which disclosing more information at the application stage $r$ may increase callback rates (Abel et al., 2020). In our paper, we show that the unemployed can greatly benefit from a well-designed promotional video. More importantly, we show that workers with a visible disability benefit just as much. In particular, callback rates able bodied (disabled) applicants increase from $45 \%$ to $55.3 \%$ (19.9\% to $27.4 \%)$, a $22.8 \%(37.7 \%)$ increase. ${ }^{3}$ Finally, we provide a back of the envelope calculation suggesting that publicly funding the production of video resumes in the current labor market would pay for itself if they expedite exits from unemployment by as little as two weeks.

The paper is organized as follows. Section 2 presents the experimental design of our two field experiments and procedures. Section 3 presents the callback rates and results on the viewing activity. Section 4 concludes.

\footnotetext{
${ }^{2}$ Goldin and Rouse (2000) suggest that blind auditions to hire musicians are effective in reducing hiring discrimination.

${ }^{3}$ In comparison, Abel et al. (2020) find that including a reference letter increases the probability of receiving a response by 2.5 percentage points (from $4.2 \%$ to $6.7 \%$ ), a $60 \%$ increase. The large difference with our own findings is presumably due to differences in local labor markets. They conducted their experiment in South Africa whereas ours was conducted in Quebec in the context of a severe labor shortage.
} 


\section{Experimental design}

Our design involves two field experiments conducted sequentially - the benchmark experiment and the video experiment. The benchmark experiment allowed us to measure baseline callback rates of persons with and without disabilities. These rates were used to parameterize the video experiment so as to attain adequate statistical power. The benchmark experiment also covered a broader set of jobs than the video experiment, allowing some robustness checks regarding callback rates.

Both experiments focused on wheelchair users because they are presumably as productive as able bodied workers in many settings. This was assessed using the O*NET database which contains a rich set of variables describing worker characteristics, skill and physical requirements of most occupations. ${ }^{4}$ We focused on the following four important physical attributes: 1) bending and/or twisting of the body; 2) kneeling, crouching, stooping or crawling; 3) standing; 4) walking or running. Each attribute is rated on a scale from 0 to 100 . The following occupations were selected as they are relatively common have very low physical requirements: secretaries, receptionists, computer programmers, and accounting clerks. Indeed, scores for bending or twisting varied between $4 / 100$ for accounting clerks to $17 / 100$ for receptionists, whereas those for kneeling or crouching ranged from $3 / 100$ for accounting clerks to $11 / 100$ for receptionists. Hence, it can safely be assumed that the use of a wheelchair should have little if any effect on productivity in these occupations. We next describe both experiments in more detail.

\subsection{Benchmark experiment}

Our fictitious applicants focused on jobs posted within a 100 kilometer radius of Montréal and Québec City (Canada). The CVs were designed in collaboration with a local com-

\footnotetext{
${ }^{4}$ Information and data can be found on the following page O*NET 23.3 Database of the U.S. Department of Labor, Employment and Training Administration (USDOL/ETA). Used under the CC BY 4.0 license.
} 
munity organization (La Croisé) whose mission is to assist disabled workers in their job search. We were provided with a set of anonymized CVs drawn from their archives. These were used to generate representative CVs using a custom computer program. ${ }^{5}$

Each application contained two pages: a cover letter and a resume. The computer program was designed so as to determine application-specific inputs (occupation, spoken and written languages, etc.), and varied other components randomly. ${ }^{6}$ The Appendix provides an example of a typical cover letter (translated into English). The male and female fictitious applicants were named "Jonathan Gagnon" and "Jessica Gagnon", respectively. "Gagnon" is among the most common surname in the province of Québec, while Jessica and Jonathan are among the most common female and male given names, respectively. A name-specific phone number was assigned to each and a gender-specific voice message was recorded by individuals in their early thirties, the average age of our fictitious applicants (see below). The voice mail messages simply stated: "Hello, this is Jessica (Jonathan) Gagnon. Please leave a message and I will call you back shortly". The same e-mail address was used for all applicants (i.e. jgagnon35@hotmail.com).

The cover letters highlighted past voluntary work as well as written and spoken fluency in both French and English. Mention of wheelchair use was randomly assigned across cover letters as follows: "I would like to mention that, following an accident in year $X, I$ am using a wheelchair. Please note that this does not impair the quality of my work in

\footnotetext{
${ }^{5}$ The computer program is a Python script. For each application, the program (1) randomly generates each applicant's characteristics, (2) generates a cover letter and resume in a LaTeX file containing a numerical identifier in the application's file name and (3) writes a database that links the applications identifier to its characteristics. All .tex files are then compiled into .pdf files with LaTeX. The numerical identifier is removed from the name of the .pdf file before it is sent to the employer.

${ }^{6}$ Other components include included gender (when relevant), availability of a government sponsored subsidy, and work history (years of experience, unemployment spells). An unpublished working paper using data from the benchmark experiment documents that none of these variables significantly determine callback rates (see Bellemare et al. (2018) for details). The computer program ensured consistency between all components of the CV. For example, work experience could not begin before education and training had ended.
} 
any way". Year $X$ was randomly selected under specific logical constraints. ${ }^{7}$ Varying $X$ allowed to test whether callback rates varied with the duration of the disability. Discussions with La Croisé stressed that, while some applicants abstain from mentioning their disability by fear of discrimination, many prefer to mention it in their cover letters so as to avoid the burden of visiting a firm that is either not accessible or unwilling to accommodate their specific needs.

For each occupation we generated resumes with relevant academic degrees and work experience. The Appendix provides an example of a typical resume (translated into English). In addition to the name and contact information, the resumes were structured as follows: Education always appeared at the top of the resume and included both a high school and a post-secondary degree. Computer programmer applications additionally mentioned either a post-secondary (community college) diploma or a university degree, depending on the requirements. They also indicated an internship in a fictitious firm during the last year of schooling, as this is standard practice in this field. In all cases, the diplomas mentioned existing schools names within the target city. The year the last diploma was awarded was randomly generated and all the other years mentioned in this section were determined accordingly as a function of the diplomas' standard completion times. ${ }^{8}$ Employers may use this information to infer the age of the candidate (It is very uncommon to state one's age in a resume in Québec.). ${ }^{9}$

Professional experience followed immediately after education, followed by computer skills (all resumes indicated "Office Suite"), language skills and hobbies.

\footnotetext{
${ }^{7}$ Year $X$ is constrained to be greater than the year of birth that could be inferred by the employer from the starting year of high school that appears in the resume (see below). It is also constrained to be smaller than the year the resume is sent.

${ }^{8}$ For example, take a resume for an accounting clerk with a diploma awarded in 2007. The standard duration includes a five-year high-school diploma and a three-year college diploma. In this example, the resume would state high-school attendance from 1999 to 2004 and community college training from 2004 to 2007.

${ }^{9}$ For example, consider a resume sent in 2016. If the resume indicates that high-school lasted between 1999 and 2004, and considering high-school usually starts at age 12, the employer may reasonably infer that the candidate is about 29 years old (2016-1999+12).
} 
Overall, 1,477 applications were sent between May 2016 and April 2017 to positions advertised through on-line job search engines (Indeed.ca, emploiquebec.gouv.qc.ca). We excluded job offers that had been posted for more than two weeks in order to focus on employers with potential vacancies. A single resume was sent to each position. ${ }^{10}$ Employers could leave a message on the candidate's answering machine or send an e-mail to either convene him/her to a formal interview or to ask for additional information. In order to limit their burden, the employers where informed by email within 48 hours that the candidate had found another job and was therefore not interested in pursuing matters further.

\subsection{Video experiment}

The video experiment focused exclusively on secretary and receptionist positions. This decision was made after conducting a power analysis prior to the experiment (see below). This analysis suggested sufficient power could be achieved mostly for these positions given the expected number of job postings that were observed in the benchmark experiment. The experiment involved sending three types of applications. The first type involved a cover letter and resume not mentioning a disability. The second type of application disclosed a disability through the cover letter by stating "Being a person in a wheelchair, I am accustomed to overcoming numerous challenges" (translated from French). The first two types mimicked those sent in the benchmark experiment.

The third type of application invited firms to use a hyperlink to view a video resume. Importantly, no disability was disclosed through the cover letter of these applications. This information could only be assessed by viewing the video resume. Cover letters included the following statement: "In order to introduce myself, I have prepared a video resume that I invite you to view by clicking here" (translated from French). Templates of cover letters and resumes used in the video experiment are presented in the

\footnotetext{
${ }^{10}$ The rationale for this is to avoid spillover effects. Indeed, Phillips (2019) shows that experiments in which multiple fictional applications are sent to the same employer may confound discrimination and individual's characteristics with employers responses to the composition of the applicant pool.
} 
appendix. They follow corresponding templates used for the benchmark experiment, changing the name of the fictitious candidate (Rosalie Côté).

A female actress was recruited through a local acting agency based in Québec city. The agency proposed five candidates who had formal training. The actress who was recruited had limited acting visibility, having only taken part in a short 15 second commercial several years prior to the experiment. Acting gigs represent windfall gains for actors of this agency who otherwise occupy regular jobs. ${ }^{11}$ The actress was provided a script and recording took place on a single day in June 2017 in a professional studio located on the premise of Université Laval.

Two takes were recorded. In the first, the actress was instructed to sit in a regular office chair and to read the script aloud. ${ }^{12}$ The second take used the same script except that the actress was instructed to sit in a wheelchair. Each take was recorded using both a wide and a narrow frame using a high-resolution professional camera equipped with a microphone. Narrow frames focused on the head and upper torso of the actress, thus not revealing the chair the actress was sitting on, whereas wide frames did so. In both takes the actress was then filmed in a regular office setting typing on a laptop and answering phone calls while sitting behind a standard desk. The office settings aimed at providing a dynamic feel to the videos. They were also meant to highlight the fact that wheelchair users do not generally require specific workplace accommodations either in terms of furniture or equipment.

Raw takes were edited to produce four video resume types lasting 1 minute and 24 seconds each. Video types varied along two dimensions: 1) disclosure or not of a disability and 2) early or late switch from narrow to wide framing, exoogenously varying timing revelation of the disability for videos disclosing one. Figure 1 presents the video resume timeline and Figures 4, 5 and 6 show snapshots of the main sequences of our video resumes. All four videos started with the narrow frame (Figure 4), not revealing the chair the actress was sitting on. Revelation of the disability occurred when

\footnotetext{
${ }^{11}$ The actress we recruited is a full-time secretary in a dental clinic in Québec city.

${ }^{12} \mathrm{~A}$ translated version of the script can be found in the appendix.
} 
the scenes switched from the narrow to the wide frames (see Figure 5a for the resume without disability and Figure 5b for the resume with disability). "Early" revelation occurred at 13 seconds while "late" revelation occurred at 51 seconds. Office takes started respectively at seconds 17 and 55 (early/late revelation) and ended respectively at seconds 30 and 67 (see Figure 6a for the resume without disability and Figure 6b for the resume with disability). We define "disability revelation" zones for early/late videos as the segment starting at the transition from narrow to wide frames (13 and $51 \mathrm{sec}-$ onds, respectively) and ending with the conclusion of each office scene (30 and 67, respectively). Naturally, callback rates are not expected to vary over revelation zones for videos that do not disclose a disability. We hypothesize that late revelation may help the candidate convince viewers that she possesses the required skills prior to revealing her disability. A convinced viewer may be more reluctant to turn down her candidacy.

Early revelation video

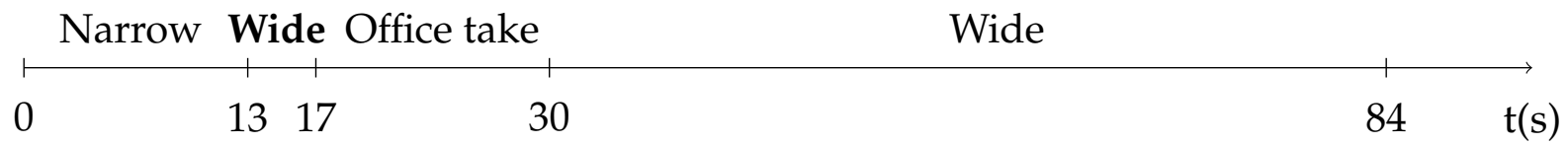

Late revelation video

\begin{tabular}{lllllll} 
Narrow & \multicolumn{4}{c}{ Wide Office take } & Wide & \\
\hline 0 & , & , & , & & \\
\hline & 51 & 55 & 67 & 84 & $\mathrm{t}(\mathrm{s})$
\end{tabular}

Figure 1: Video timelines for early/late revelations

Firm specific internet links were incorporated in the cover letters of applications. Firms that were randomized to receive an invitation to view a video resume were then randomly assigned one of 4 video resume types described above. Viewing statistics such as the number of views, viewing duration, scrolling activity, etc. were recorded. 
All four video types can be viewed by visiting the following link: https:/ /www.deppi.org/videoexperiment. ${ }^{13}$ We used the computer infrastructure of the benchmark experiment to generate applications of the video experiment (see discussion above).

\subsection{Power analysis}

Our aim is to detect with sufficiently high sampling probability differences in callback rates 1) between applications including and not including a video resume, 2) between application disclosing or not a disability and 3) in the effect of video resumes for these two populations. Prior to the video experiment, we conducted a power analysis based on the results from the benchmark experiment to assess the distribution and number of application types that should be sent. The basic power analysis was based on the following probit model :

$$
\operatorname{Pr}(\text { callback } \mid \text { video, disability })=\Phi\left(\beta_{0}+\beta_{1} \text { video }+\beta_{2} \text { disability }+\beta_{3} \text { video } \times \text { disability }\right)
$$

where video and disability are two dummy variables. We used secretary and receptionist callback rates from the benchmark experiment to obtain calibrated values ( $\beta_{0}=$ $\left.-0.412, \beta_{2}=-0.763\right)$. We considered values of $\left(\beta_{1}=0.483, \beta_{3}=-0.366\right)$ which are consistent with video resumes increasing callback rates of persons with and without disabilities by 2.5 and 5 percentage points respectively. These values were set assuming video resumes could possibly be less effective when revealing a physical disability. We conducted the power analysis using simulation methods by assigning no invitation to click and view a video resume to $25 \%$ of applications (this subset being equally split between both disabled and non-disabled populations). $75 \%$ of applications were assigned an invitation to view a video resume, this subset being equally split across both populations and early/late revelations. An experiment is considered to have sufficient power when it can detect a treatment effect of interest with at least $80 \%$ sampling prob-

\footnotetext{
${ }^{13}$ Viewing activity of videos on this web site is not recorded.
} 
ability (see Bellemare et al. (2016) for a discussion). The analysis revealed that power would exceed 90\% (two-sided tests) for all model parameters in (1) when sending 2000 independent applications using the distribution of application types outlined above. ${ }^{14}$

Extending the power analysis to account for early/late revelation of a disability requires some assumptions about the expected effects of this treatment variation. As argued above, it seems reasonable to assume that this change should not affect callback rates when no disability is revealed. We extended the power analysis to account for a possible effect of early/late revelation for persons with disabilities. We did this by adding $\beta_{4}$ video $\times$ disability $\times$ late as an explanatory variable in (1), where late denotes a dummy variable for videos with late revelation. We set $\left(\beta_{4}=0.3666\right)$ which implies that late revelation of a disabilities allows the effect of video resumes to match those of persons without disabilities. Simulated power of the extended model remained in excess of $90 \%$ for all parameters when sending 2000 applications as described above. These results validate the design of the video experiment as well provide a target sample size for the experiment.

We therefore sent 2021 applications between September 2017 and August 2018. Of those, 569 applications (311 and 258 with/without a disability) contained no video resume. The remaining 1452 applications (719 and 733 with/without a disability) included a video resume, half of which switched from a narrow to a wide frame after 51 seconds instead of 13.

\subsection{Workplace accessibility}

An important issue to interpret callback rates of wheelchair users is to control for wheelchair accessibility, which may artificially decrease callback rates of applications indicating a physical disability. We investigated this issue for 611 of the 1477 firms in

\footnotetext{
${ }^{14}$ Power was simulated using 1000 samples drawn from (1) for a range of sample sizes.
} 
the benchmark experiment and 1788 of the 2021 firms in the video experiment. ${ }^{15}$ To proceed, a first assessment was conducted using Google street view when possible. For some firms, this first assessment allowed to establish without ambiguity whether their office buildings offered adequate access to wheelchair users. Firms which could not be conclusively assessed via Google street were subsequently visited by research assistants to determine their accessibility. To be considered accessible, offices needed to be housed in buildings with an access ramp. Moreover, firms whose offices were situated above the ground floor level required an elevator to be considered accessible. Figure 3 presents the map of firms that were visited (crosses) or not (grey markers) for metropolitan areas of Montréal and Québec city. We find that the geographic centers of both areas are relatively well covered.

In the benchmark experiment, we find that $71 \%$ of the 611 visited firms are accessible whereas in the video experiment, $57 \%$ of the 1788 visited firms are accessible.

\section{Results}

Our main analysis considers an application as successful if it received a request for additional information or a formal job interview, which can be seen as a broad definition of positive job search outcomes. We also conducted a robustness analysis using a narrow measure of a positive outcome restricted to a formal request for a job interview. For brevity, all tables in the paper using as input callback rate data are reproduced in the online appendix using the narrow outcome measure. Results are largely robust to the measure used.

We begin by discussing callback rates for applications with and without a video resume. We then provide evidence that individuals with disabilities are discriminated on the labor market and show to what extent video resumes can increase callback rates

\footnotetext{
${ }^{15}$ For the benchmark experiment, we inspected almost all firms in the metropolitan area of Québec City and none in the metropolitan area of Montréal, while we covered both metropolitan areas in the video experiment.
} 
for this population. We finally discuss viewing activity of the potential employers and provide insights on how they may respond differently to videos revealing a disability.

\subsection{Descriptive evidence}

Figure 2 presents callback rates in both our experiments broken down by disability status. Red bars present rates for our benchmark experiment where no video resumes were sent. Dark blue bars present corresponding callback rates in the video experiment when firms where not invited to click and view a video resume. Callback rates in the video experiment are higher for both populations relative to the benchmark experiment. We attribute these increases mostly to labor market tightness - the unemployment rate in the province of Quebec decreased from 7.1\% in 2016 (beginning of our benchmark experiment) to 5.1\% in 2019 (end of the video experiment).

Light blue bars present callback rates when firms were invited to click and view a video resume. We find that callback rates for non-disabled and disabled populations significantly increase ( $p$-values of respectively 0.004 and 0.011 , two-sided tests) relative to firms not invited to view videos in the same experiment (dark blue bars). The effects of video resumes are quantitatively large. Including a video resume in the application increases the callback rate by around 10 percentage points for both populations: for non-disabled applicants, it increases from from $45 \%$ to $55.3 \%$ (a $22.8 \%$ increase), while it increases from $19.9 \%$ to $27.4 \%$ (a $37.7 \%$ increase) for disabled applicants.

Table 1 presents callback rates for applicants without disabilities (Column a) broken down by experiment and targeted positions. Differences in callback rate levels for applicants with a disability relative to no disabilities (Column b), callback rate ratios (Column c), and sample sizes (Column d) complete the Table.

We find a sizeable and significant callback rate gap between applicants revealing or not a disability ( $25.2 \%$ and $52.7 \%$ respectively) in the video experiment which targeted secretary-receptionist positions exclusively.

This result is consistent with the benchmark experiment where we observe a sim-

ilarly large callback rate gap for the same targeted positions. Callback ratios suggest 
that callback rates of non-disabled applicants for secretary-receptionist positions are at least twice those of disabled applicants in both experiments. Although weaker, callback rate gaps and ratios are also large for other targeted positions in the benchmark experiment, suggesting firms seeking secretary-receptionist positions do not have unrepresentative recruitment practices than those seeking to fill other positions.

Finally, the last panel of Table 1 pools data from both experiments to assess differences in callback rates across firms offering or not wheelchair access. The difference in callback rates between disabled and non-disabled applications remains high even amongst accessible firms. Our results thus suggest that accessibility problems are not a major driving force behind observed differences in callback.

\subsection{Regression analysis}

Table 2 presents the estimated effects of applications' and firms' characteristics on callback rates using linear probability models. ${ }^{16}$ Columns (a) to (d) present estimates using data from the video experiment. Column (a) presents a specification including only a binary variable indicating whether or not firms received an invitation to click and view a video resume, where the constant captures the callback rate for the reference group (applications without video resume). Results suggest an estimated callback rate of $31.3 \%$ for resumes without a video. The callback rate when inviting firms to click and view a video resume is estimated to be $41.5 \%$, a 10.2 percentage points increase relative to applications not offering firms to view a video resume.

The next columns allow for separate effects of the videos for applications revealing or not a disability. Column (b) adds a binary variable indicating whether a disability is revealed as well as an interaction of the latter with the video dummy. Estimates suggest that the effect of the video resume does not vary significantly with disability status. This result is robust when including a binary variable to control for wheelchair

\footnotetext{
${ }^{16}$ Parameter estimates are very similar in magnitude and significance to the average marginal effects obtained from a probit model (available upon request). The linear probability model has the additional advantage of simplifying the interpretation of interaction effects.
} 
access (Column c). ${ }^{17}$

As indicated in Section 2, half of the video resume invitations switched from a narrow to a wide frame (i.e. after 51 second instead of 13) in order to vary when the applicant's chair (wheelchair or not) became visible. It is hypothesized that late revelation of a disability could result in lower discrimination given viewers have more time to appreciate the qualifications of the applicant before being possibly disrupted by this revelation. We test this hypothesis by interacting a dummy variable for late revelation with the interaction of video and disability dummies, but find no significant effect of revealing the disability later. ${ }^{18}$

Finally, because our result on the non-statistical significance of the effect of firms' accessibility could be driven by the number of observations, Column (e) presents an estimation on the data from both our video resumes and our benchmark experiments. We use only the secretary-receptionist positions from the benchmark experiments in order to make our two samples more comparable, but including all professions and controlling for professions using dummy variables gives similar results (available upon request). The estimation includes a dummy variable that equals one for observations from the video experiment. Its positive estimated effect likely captures the lower unemployment level in Quebec at the time we conducted this experiment. The estimated effects from Column (e) show that our results discussed above are robust to including these observations.

Siegelman and Heckman (1993) and Heckman (1998) have argued that estimates of discrimination using correspondence studies can potentially be biased in unknown directions. Their critique is based on a structural model assuming employers interview applicants when productivity of the later exceeds a given threshold. In this model, biases arise when the discrimination effect is estimated using standard methods (e.g. linear probability model or probit/logit) and the variance of the applicants'

\footnotetext{
${ }^{17}$ Lower sample size when controlling for accessibility reflects the fact that we were able to get this information only for a subset of applications. See section 2 for details.

${ }^{18}$ We also tested whether early / late revelation influenced callback rates when no disability is revealed. No significant effect was detected
} 
unobserved productivity differs across the reference group and the potentially discriminated group. The sign of the bias depends on the relative quality of fictitious applications compared to real applications employers usually receive. If fictitious applications are of high (low) quality, so that the average applicant is expected (not) to be productive enough, then a higher variance of the error term decreases (increases) the probability that the applicant's productivity is at least equal to the threshold and that the applicant is called back. In that case, even if the average applicant is perceived to have the same productivity in both groups, the group with the highest variance will have a lower (higher) callback rate. Neumark (2012) presents an approach to decompose the estimated discrimination effect into a level effect (i.e the effect of disability on the level of the latent variable in the structural model) and a variance effect (i.e. the effect of a greater variance of the error term that would affect the probability of exceeding the threshold), the latter being possibly an artifact of the study design. The approach is based on a binary choice model which allows the variance of the error term to differ between populations of interest. The main identifying assumption is that the effect of at least one variable should be restricted to be the same for both the reference and the potentially discriminated group. We therefore estimate the following heteroscedastic probit model:

$$
P(\text { callback } \mid d, x)=\Phi\left(\frac{\beta_{0}+\beta_{1} d+\beta_{2} x}{\exp (\theta d)}\right),
$$

where $d$ is the disability dummy variable and $x$ is a control variable restricted to have the same effect for disabled and non-disabled applications. Identification of the model parameters given this restriction is straightforward. Regression of callback rates on $x$ for the subgroup of applications not revealing a disability identifies an intercept $\beta_{0}^{N D}=$ $\beta_{0}$ and a slope parameter $\beta_{2}^{N D}=\beta_{2}$. The same regression restricted to the subgroup of applications revealing a disability identifies an intercept $\beta_{0}^{D}=\frac{\beta_{0}+\beta_{1}}{\exp (\theta)}$ and a slope parameter $\beta_{2}^{D}=\frac{\beta_{2}}{\exp (\theta)}$. The ratio $\beta_{2}^{N D} / \beta_{2}^{D}$ identifies $\exp (\theta)$ given the restriction that $\beta_{2}$ does not vary across subgroups. Given identification of $\beta_{0}, \beta_{2}$, and $\exp (\theta)$, it is possible to back out $\beta_{1}$ from $\beta_{0}^{D}$.

We estimate the heteroscedastic probit model using two different control variables 
$x$. Column (a) of Table 3 presents estimates combining data from both experiments where $x$ is a binary variable taking a value of 1 for applications in the video experiment, and a value of 0 for applications in the baseline experiment. Column (b) restricts the analysis to data from the video experiment, where $x$ denotes the dummy variable identifying applications where firms received an invitation to click and view a video resume. We find no significant evidence that the variance of unobservables is related to disability status across both specifications. These results suggest that differences in callback rates between applications revealing or not a disability capture genuine discrimination rather than specific elements of our experimental design.

\subsection{Viewing activity and callback rates}

1452 of 2021 firms in our video experiment received an invitation to click and view a video resume. Various elements of the viewing activity of each firm were recorded, including the number of times each link was clicked, parts of the video that were viewed, and scrolling activity. The later allows us to identify when and how often videos were paused as well as contents of each video that were either scrolled to or jumped over.

Table 4 presents descriptive statistics of viewing activity in the experiment. Separate statistics are presented for videos not revealing (numbers not in brackets) and revealing a disability (numbers in brackets). Columns present corresponding sub-sample means, medians, as well as minimum and maximum values. Videos are on average viewed 1.360 times when no disability is revealed, compared to 1.306 times when a disability is revealed. Median viewing frequency is unity regardless of whether a disability is revealed, reflecting that a large share of firms do not view their video more than once, if at all. In fact, close to one third of all firms (35.74\% and 33.94\% with/without disability revelation respectively) never clicked to view the video resume. Table 4 also reveals that some videos are viewed up to 8 or 15 times depending on whether a disability was revealed. These numbers should be interpreted with caution given the small number of firms with such high viewing frequency. ${ }^{19}$ It is important to men-

\footnotetext{
${ }^{19}$ Only 1 (1) firm viewed 8 (15) times a resume without (with) revelation of a disability.
} 
tion that we are unable to identify whether the same person viewed the same video more than once as applications may have been dispatched to multiple members of a HR department or recruiting committee.

Table 4 also presents information about viewing at the intensive margin, measured by computing within each firm the median viewing shares. Similarly, we compute within firm median viewing shares of the revelation zone. We find considerable heterogeneity of viewing at the intensive margin. While firms viewed on average between $84.4 \%$ and $86.3 \%$ of all videos (depending on revelation of a disability), minimum viewing shares suggest some firms clicked and viewed only a small portion of the video they received. These results also hold when focusing only on the median share of the revelation zone viewed. Finally, Table 4 presents two other descriptors of viewing activity including pausing and scrolling back within the revelation zone. We find very little evidence that firms systematically paused and scrolled across the revelation zone. Note that we find a slightly higher number of pauses in the revelation zone and scrolls to the revelation zone when a disability is revealed.

We next analyze how the intensity of viewing activity relates to callback rates. To proceed, we categorize viewing practices to summarize viewing intensity. A natural categorization follows from the way videos were structured. Recall that all videos began with a close-up shot of the actress preventing any disclosure of a disability. Videos subsequently switched from the narrow frame to the wide frame to reveal or not a disability. This revelation was immediately followed by short takes in an office setting, showing the actress typing on a computer and answering the phone. We refer to this segment of the video as the "revelation zone". Videos subsequently concluded in a wide frame, exposing or not a disability. We group the viewing activity of each firm in one of five categories. The first category contains firms that did not click to view the video. The second category contains firms that started viewing their assigned video yet stopped viewing before reaching the revelation zone. Our third category contains firms which started viewing the video and interrupted their viewing somewhere inside the revelation zone. These firms were thus able to observe whether or not the 
actress was disabled. The third category contains firms who completed viewing of the revelation zone, yet did not finish the video. Finally, we have firms that viewed videos in their totality.

Figure 7 presents callback rates for these different categories. The figure also presents callback rates for firms in the video experiment that did not receive an invitation to view a video resume. Recall that a subset of firms in the later group were told in the cover letter that the candidate was in a wheelchair. We find that callback rates of firms that did not click to view their videos are nonetheless positive and above $20 \%$, with no significant difference between videos revealing or not a disability ( $p$-value $=0.540$, two-sided test). The later is expected given disability could only be revealed by clicking and viewing the video $\mathrm{CV}$. The positive callback rates for firms that did not click to view the video suggests that some firms probably did not notice the invitation to do so. At the same time, callback rates for firms that did not view the video are significantly below the corresponding rates for firms who did not receive an invitation to view a video and also were not told the candidate was in a wheelchair ( $p$-value $=0.000$, two-sided test). Presumably, some firms had already filled their positions when they received our applications.

Our second category contains firms that clicked to view their videos but stopped before reaching the revelation zone. There are relatively fewer firms in this category - 19 and 27 firms respectively received a video with and without revelation of a disability. We find that callback rates for these firms increase relative to firms that did not click to view their videos, suggesting that the content of the video (although partially viewed), was sufficient to trigger increases in callback rates. Again, callback rates for this category of firms are not significantly related to whether or not videos contained a revelation of a disability ( $p$-value $=0.369$, two-sided test). The increase in callback rates is sustained beyond the revelation zone when videos do not reveal a disability. This is reflected in a positive relationship between median shares of the videos viewed and callback rates, suggesting that the greater the interest in viewing the video, the greater firms are willing to request an interview. However, a striking feature of Figure 7 is that 
this relationship does not hold for videos revealing a disability. A total of 133 firms began viewing the revelation zone disclosing a disability and stopped viewing before the end of the zone. We find a significant drop in callback rates for these firms relative to the preceding category of firms ( $p$-value $=0.369$, two-sided test). Also, the difference in callback rates with and without revealing a disability are now significantly different for firms within this category ( $p$-value $=0.000$, two-sided test). Moreover, we find a slight upward trend in callback rates for firms in the remaining two categories. However, the gap in callback rates for firms that viewed or not a disability remains significant in the other two categories ( $p$-value $=0.000$, two-sided test for both categories), thus providing more direct evidence of discrimination facing persons with disabilities. More importantly, callback rates for the five categories are never below the corresponding rate where a disability is disclosed through the cover letter rather than through the video.

\subsection{Comments on videos}

19 firms provided comments on the video resume they received when reaching out to the fictitious candidate either to request additional information or to decline/invite the candidate for an interview. The appendix provides translated excerpts (from french) of these comments for the 19 firms. We note that the vast majority of these comments underline the effectiveness of the video in communicating information. Some firms also mention the novelty feature of the video resume. Although far from a comprehensive description of the perceptions of firms in our sample, these comments nonetheless reveal that video resumes are effective at signaling productivity, professionalism, and originality.

\section{Conclusion}

Results presented in this paper are the first we are aware of to document the usefulness of video resumes to facilitate matching of workers to firms. Interestingly, benefits of 
the video resume also extend to persons with a physical disability of the type we analyzed in this paper. This is an important finding considering the additional challenges facing this segment of the population. At a deeper level, it can be argued that hiding a disability (or any other trait firms may discriminate on) yields higher callback rates. At a first glance our results support this argument - callback rates are at their highest when the applicant uses a video resume without revealing a disability. Correspondence studies capture the first part of the recruitment process, but say very little about outcomes of follow-up on site job interviews. Cahuc et al. (2019) show that absence of discrimination at the invitation stage may conceal significant discrimination at the hiring stage. Since video resumes allow prospective employers to see and hear applicants, we conjecture this may lead to better matches at the interview stage and increase interview performance and outcomes. This service should be all the more relevant for persons with disabilities as they face higher mobility costs to commute to work and to undertake interviews. Video resumes represent an efficient way for them to quickly identify firms willing and able to recruit and hire persons with disabilities. Moreover, they can better approach formal on site job interviews knowing the firm they visit is aware and very likely willing to accommodate their disability.

For these reasons, public authorities may find it useful to consider broadly financing this service if returns to such financing are positive. The non-profit organization we partnered with for this project currently charges approximately $300 \$$ to produce a video CV. In comparison, social welfare benefits of single adult with and without disabilities in Québec are currently 690\$ and 1088\$ respectively. A back of the envelope calculation suggests that publicly funding the production of video resumes in the current labor market would pay for itself if video usage accelerates exits from unemployment by 2 weeks. This calculation ignores income taxes which would further increase returns to funding this service. There are numerous worthwhile extensions that should be considered in future work. First, it seems important to examine whether the service can be equally beneficial when revealing other personal characteristics such as different disabilities, ethnicities, occupations, or gender. It is important to keep in mind that 
our power analysis indicated that close to 2000 applications would need to be sent to as many firms to identify the differential effects of video resumes across two populations. It appears unlikely one can credibly conduct such an experiment by sending multiple different video resumes to each firm without risking suspicion. Hence, it seems challenging to consider testing for differential effects of video resumes for many different groups of the population in a given labor market, even when the latter is large. We conjecture that many studies will be necessary to assess these issues for the many possible groups that compose a population. Second, adoption of the service may reduce its novelty and diminish its effect relative to traditional applications that do not incorporate videos. On the other hand, widespread adoption could lead non-users to be penalized. In the latter case, the gap in callback rates between users and non-users of the service may actually increase with adoption. However, as this service undoubtedly reduces search cost through a pre-screening of candidates, theory predicts that its widespread adoption may increase labor market efficiency which could increase demand and reduce unemployment. Future work on the effects of adoption would shed light on the relative strengths of these opposing forces. 


\section{Appendix}

\section{Translated script read by the actress}

Hello, my name is Rosalie Côté and I am looking for a secretary or secretary-receptionist position.

I have many years of experience as a secretary. I can manage customer inquiries, calls, correspondences, letters and emails. I can also write and translate texts and reports.

I have a DEC (college degree) in office technology. I am quite comfortable with the Office suite and I can easily learn new software. Generally speaking, I am someone who is always looking for continuous improvement in my work. I am completely bilingual. I can answer clients and manage appointments.

Why should you choose me? Because I am a helpful person, I like helping others and that is why I volunteered to assist individuals at the Revenue Agency to prepare their tax return. I am a hardworking, reliable person who cares about doing the job correctly, and I really take to heart the success of the company where I work. 


\section{Translated comments on video resumes}

- I am really impressed by the originality of your presentation. Unfortunately, the administrative assistant position has been filled.

- I left you a message over the phone. I really liked your CV video, very current, WELL DONE!

- And congratulations on your video. I found it quite daring on your part, and above all very refreshing.

- I congratulate you on your video CV. You present yourself very well.

- I really liked your video CV!

- Thank you for your curriculum vitae, very nice presentation both through text and through video! I have a few questions for you.

- Thank you for sending me your CV, I really enjoyed your presentation video.

- We were charmed by your presentation video.

- I am taking the liberty to keep your application in the event that we need someone for a front-line customer service position (which should happen quite shortly), because your presentation is superb!

- We do not have an open position at the moment, but I wanted to tell you that your presentation is excellent, both your $\mathrm{CV}$ and your video.

- Thank you for applying. I am impressed by the professionalism of your application and your experience.

- I really like your video CV. It is the first time I receive one like this!

- I received your CV and viewed your presentation, which I loved! 
- Wow, your video CV is really cool. :)

- I received your CV and watched your video, and I think you would be a candidate worthy of our company, I quite liked it.

- I thought your video-CV was very good. It was the first time I received such a CV. It is very effective. I wonder which organization produced this video.

- I received your curriculum vitae and I really appreciated the video presentation.

- I appreciate your video presentation; however, it is important for us to have your detailed CV.

- Your keen interest in customer service, as well as your video presentation, captured our attention. 


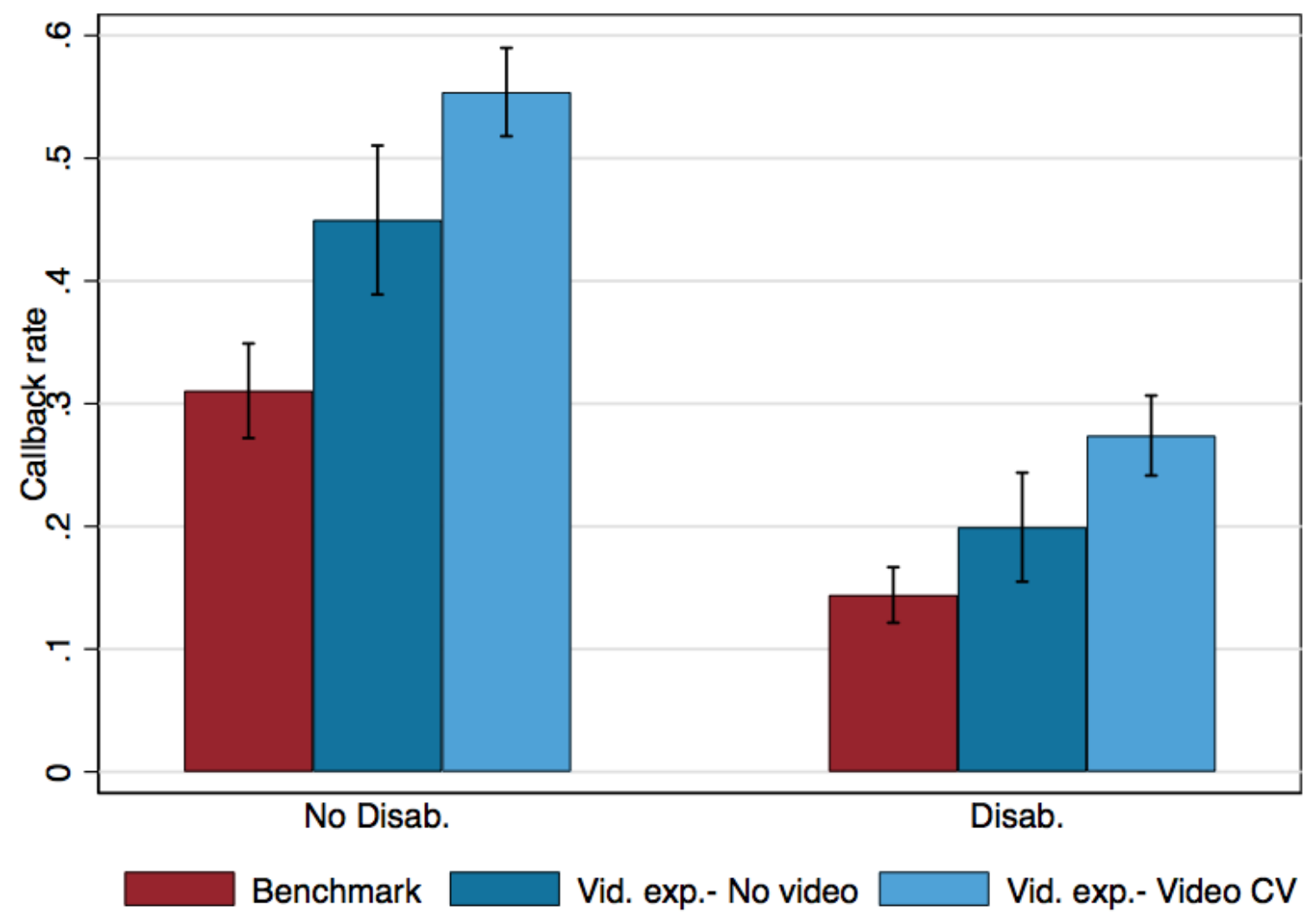

Figure 2: Callback Rates for both experiments broken down by disability status. 95\% confidence intervals for proportions shown. 


\begin{tabular}{|c|c|c|c|c|}
\hline & $\begin{array}{c}\text { Reference } \\
\text { (a) }\end{array}$ & $\begin{array}{l}\text { Diff. if disab. } \\
\text { (b) }\end{array}$ & $\begin{array}{l}\text { Ratio ref./disab. } \\
\text { (c) }\end{array}$ & $\begin{array}{l}\text { Obs. } \\
\text { (d) }\end{array}$ \\
\hline \multicolumn{5}{|l|}{ Video experiment } \\
\hline Secretary-Receptionist & 0.527 & $\begin{array}{c}-0.275^{* * *} \\
(0.022)\end{array}$ & 2.095 & 2021 \\
\hline \multicolumn{5}{|l|}{ Benchmark experiment } \\
\hline Secretary-Receptionist & 0.337 & $\begin{array}{l}-0.199^{* * *} \\
(0.030)\end{array}$ & 2.449 & 788 \\
\hline Accounting clerk & 0.264 & $\begin{array}{c}-0.190^{* * *} \\
(0.041)\end{array}$ & 3.577 & 319 \\
\hline Programmer & 0.291 & $\begin{array}{l}-0.083^{*} \\
(0.048)\end{array}$ & 1.401 & 370 \\
\hline Total & 0.310 & $\begin{array}{c}-0.166^{* * *} \\
(0.022)\end{array}$ & 2.155 & 1477 \\
\hline Both experiments & & & & \\
\hline Secretary-Receptionist & 0.481 & $\begin{array}{c}-0.265^{* * *} \\
(0.018)\end{array}$ & 2.231 & 2809 \\
\hline Not accessible for wheelchairs & 0.480 & $\begin{array}{c}-0.281^{* * *} \\
(0.031)\end{array}$ & 2.418 & 950 \\
\hline Accessible for wheelchairs & 0.500 & $\begin{array}{c}-0.263^{* * *} \\
(0.025)\end{array}$ & 2.114 & 1449 \\
\hline Total & 0.449 & $\begin{array}{l}-0.248^{* * *} \\
(0.016)\end{array}$ & 2.238 & 3498 \\
\hline
\end{tabular}

*** $p \leq 0.01 ;{ }^{* *} p \leq 0.05 ;{ }^{*} p \leq 0.1$

Table 1: Callback Rates for an Interview or for Requesting Additional Information. 


\begin{tabular}{|c|c|c|c|c|c|}
\hline & \multicolumn{4}{|c|}{ Video experiment } & \multirow{2}{*}{$\begin{array}{c}\text { Both experiments }^{\alpha} \\
\text { (e) }\end{array}$} \\
\hline & (a) & (b) & (c) & (d) & \\
\hline \multirow[t]{2}{*}{ Video } & $0.102^{* * *}$ & $0.104^{* * *}$ & $0.104^{* * *}$ & $0.104^{* * *}$ & $0.110^{* * *}$ \\
\hline & $(0.023)$ & $(0.036)$ & $(0.038)$ & $(0.036)$ & $(0.034)$ \\
\hline \multirow[t]{2}{*}{ Disab. } & & $-0.250^{* * *}$ & $-0.256^{* * *}$ & $-0.250^{* * *}$ & $-0.250^{* * *}$ \\
\hline & & $(0.038)$ & $(0.048)$ & $(0.038)$ & $(0.039)$ \\
\hline \multirow[t]{2}{*}{ Disab. $\times$ Video. } & & -0.030 & -0.026 & -0.037 & -0.037 \\
\hline & & $(0.046)$ & $(0.048)$ & $(0.049)$ & $(0.040)$ \\
\hline \multirow[t]{2}{*}{ Access } & & & 0.052 & & 0.036 \\
\hline & & & $(0.034)$ & & $(0.031)$ \\
\hline \multirow[t]{2}{*}{ Disab. $\times$ Access } & & & -0.001 & & 0.008 \\
\hline & & & $(0.044)$ & & $(0.040)$ \\
\hline \multirow[t]{2}{*}{ Disab. $\times$ Video. $\times$ Late reveal } & & & & 0.014 & \\
\hline & & & & $(0.033)$ & \\
\hline \multirow[t]{2}{*}{ Video. exp. dummy } & & & & & $0.052^{*}$ \\
\hline & & & & & $(0.028)$ \\
\hline \multirow[t]{2}{*}{ Constant } & $0.313^{* * *}$ & $0.450^{* * *}$ & $0.420^{* * *}$ & $0.450^{* * *}$ & $0.371^{* * *}$ \\
\hline & $(0.019)$ & $(0.031)$ & $(0.038)$ & $(0.031)$ & $(0.036)$ \\
\hline Observations & 2021 & 2021 & 1788 & 2021 & 2236 \\
\hline
\end{tabular}

${ }^{* * *} p \leq 0.01 ; * * p \leq 0.05 ; * p \leq 0.1$

$\alpha$ : Both experiments refers to results pooling data from the benchmark experiment and the video experiment. experiment's secretaries-receptionists observations

Table 2: Linear Probability Models. Dependent Variable: Callback for an Interview or for Requesting Additional Information 


\begin{tabular}{l|cc}
\hline \hline & $(\mathrm{a})$ & $(\mathrm{b})$ \\
\hline Disab. - level effect $\left(\beta_{1}\right)$ & $-0.843^{* * *}$ & $-0.783^{* *}$ \\
& $(0.240)$ & $(0.381)$ \\
Disab. - variance effect $(\theta)$ & 0.147 & 0.075 \\
& $(0.261)$ & $(0.523)$ \\
Vid. exp. dummy $\left(\beta_{2}\right)$ & $0.489^{* * *}$ & \\
& $(0.083)$ & \\
Video $\left(\beta_{2}\right)$ & & $0.262^{* * *}$ \\
& & $(0.091)$ \\
Constant $\left(\beta_{0}\right)$ & $-0.422^{* * *}$ & $-0.127^{* * *}$ \\
& $(0.073)$ & $(0.078)$ \\
\hline Observations & 2809 & 2021 \\
\hline \hline *** $p \leq 0.01 ; * * 0 \leq 0.05 ;{ }^{*} p \leq 0.1$ &
\end{tabular}

Table 3: Heterogenous probit estimates of the model coefficients

\begin{tabular}{lcccc}
\hline \hline & Mean & Median & Min & Max \\
\hline Number of clicks per video & $1.360[1.306]$ & $1[1]$ & $0[0]$ & $8[15]$ \\
When video clicked & & & & \\
- Median share of video viewed & $0.863[0.845]$ & $0.99[0.98]$ & $0.08[0.05]$ & $1[1]$ \\
- Median share of revelation zone viewed & $0.878[0.888]$ & $1[1]$ & $0[0]$ & $1[1]$ \\
- Number of pauses in revelation zone & $0.178[0.232]^{*}$ & $0[0]$ & $0[0]$ & $3[3]$ \\
- Number of scrolls to revelation zone & $0.108[0.189]^{* *}$ & $0[0]$ & $0[0]$ & $6[7]$ \\
\hline \hline
\end{tabular}

Statistics for videos not revealing a disability (numbers not in brackets) are presented alongside corresponding statistics for videos revealing a disability (in brackets).

Significant difference across groups ${ }^{* * *} p \leq 0.01 ;{ }^{* *} p \leq 0.05 ;{ }^{*} p \leq 0.1$.

Table 4: Summary statistics of viewing activity. 


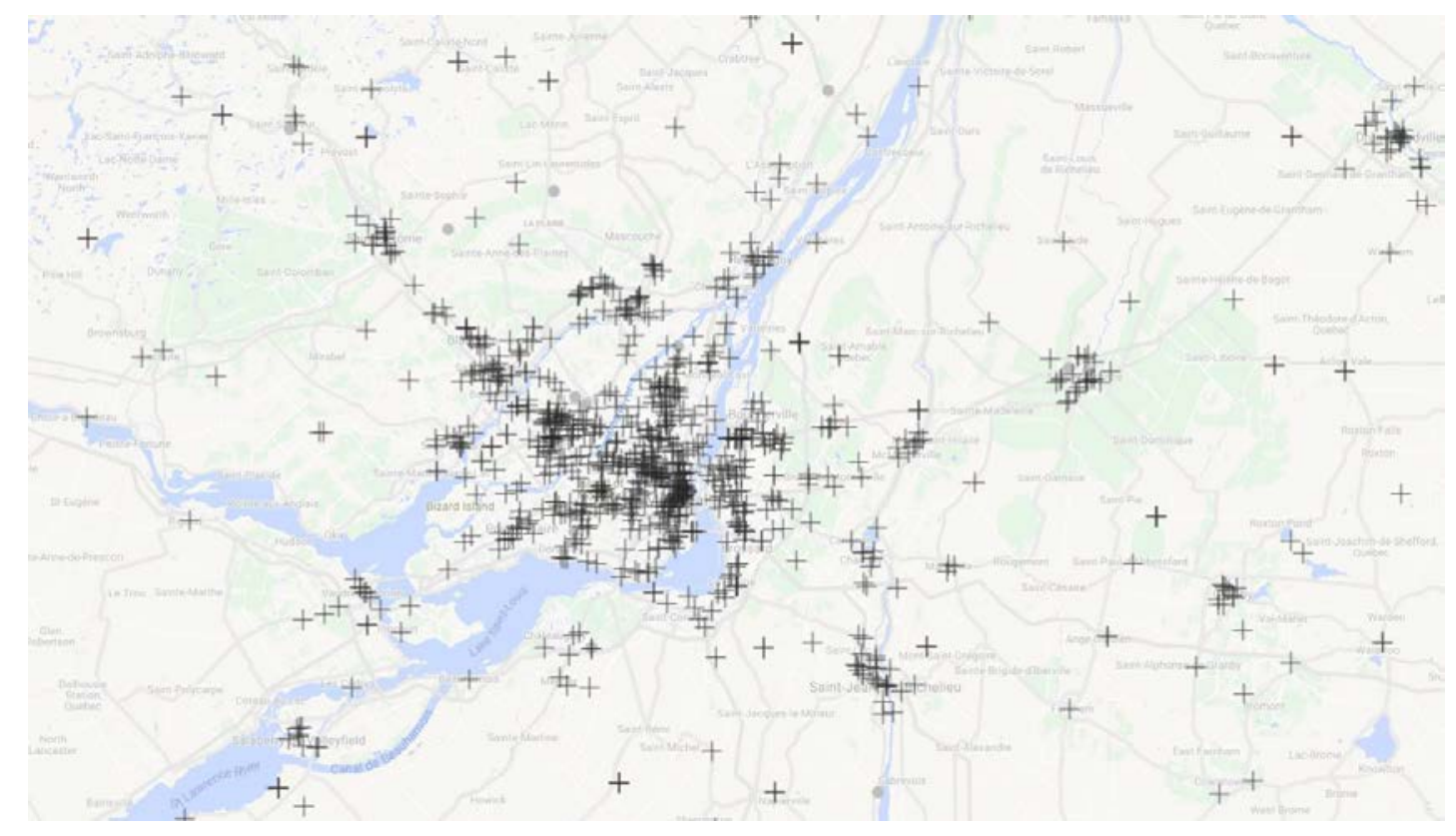

(a) Montréal

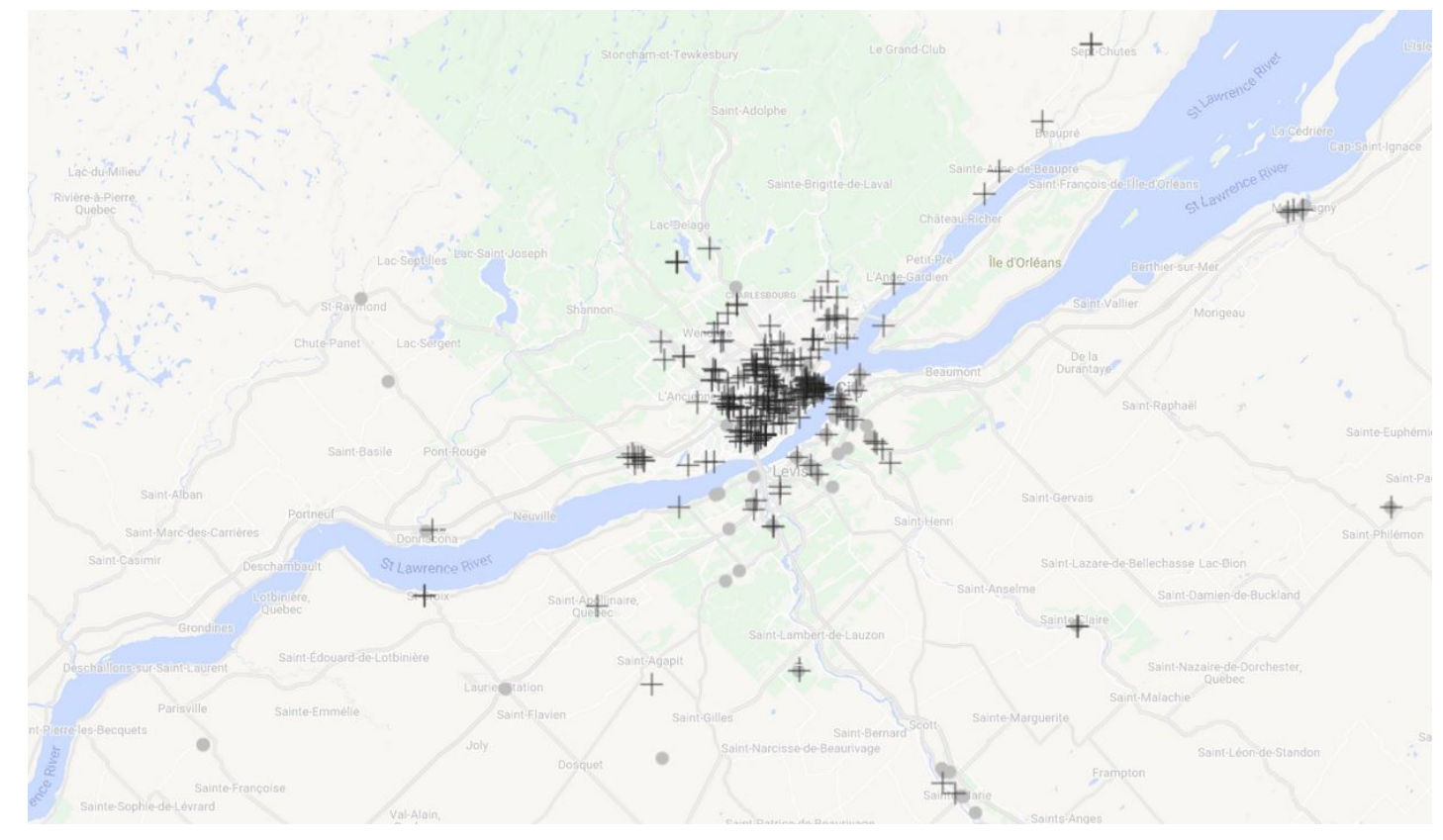

(b) Québec

Figure 3: Geographic location of firms in our sample for metropolitan areas of Montréal (panel a)) and Québec city (panel b)). Crosses (grey markers) indicate location of firms whose accessibility was (not) verified. 


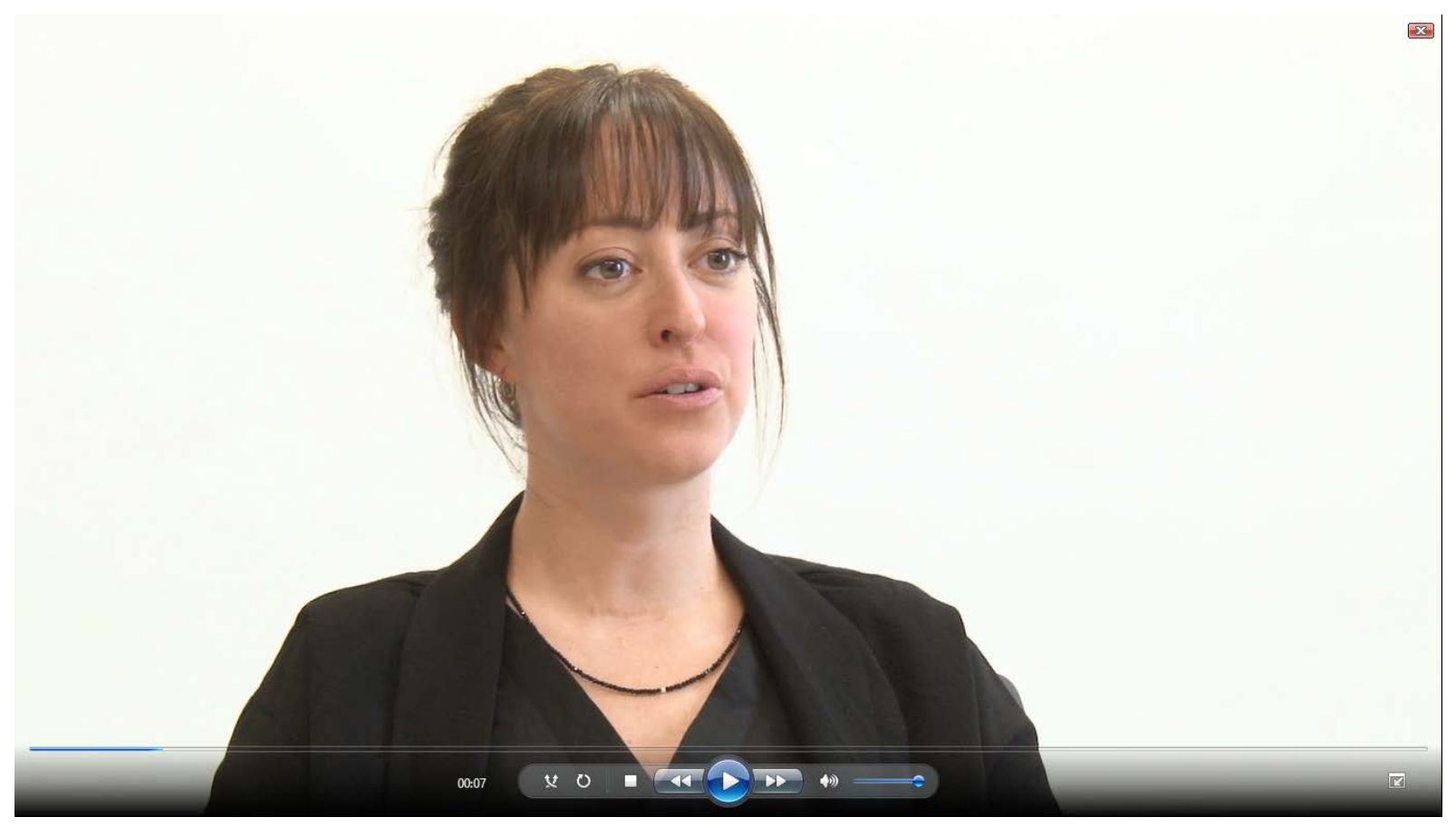

Figure 4: Video resume. Narrow frame 


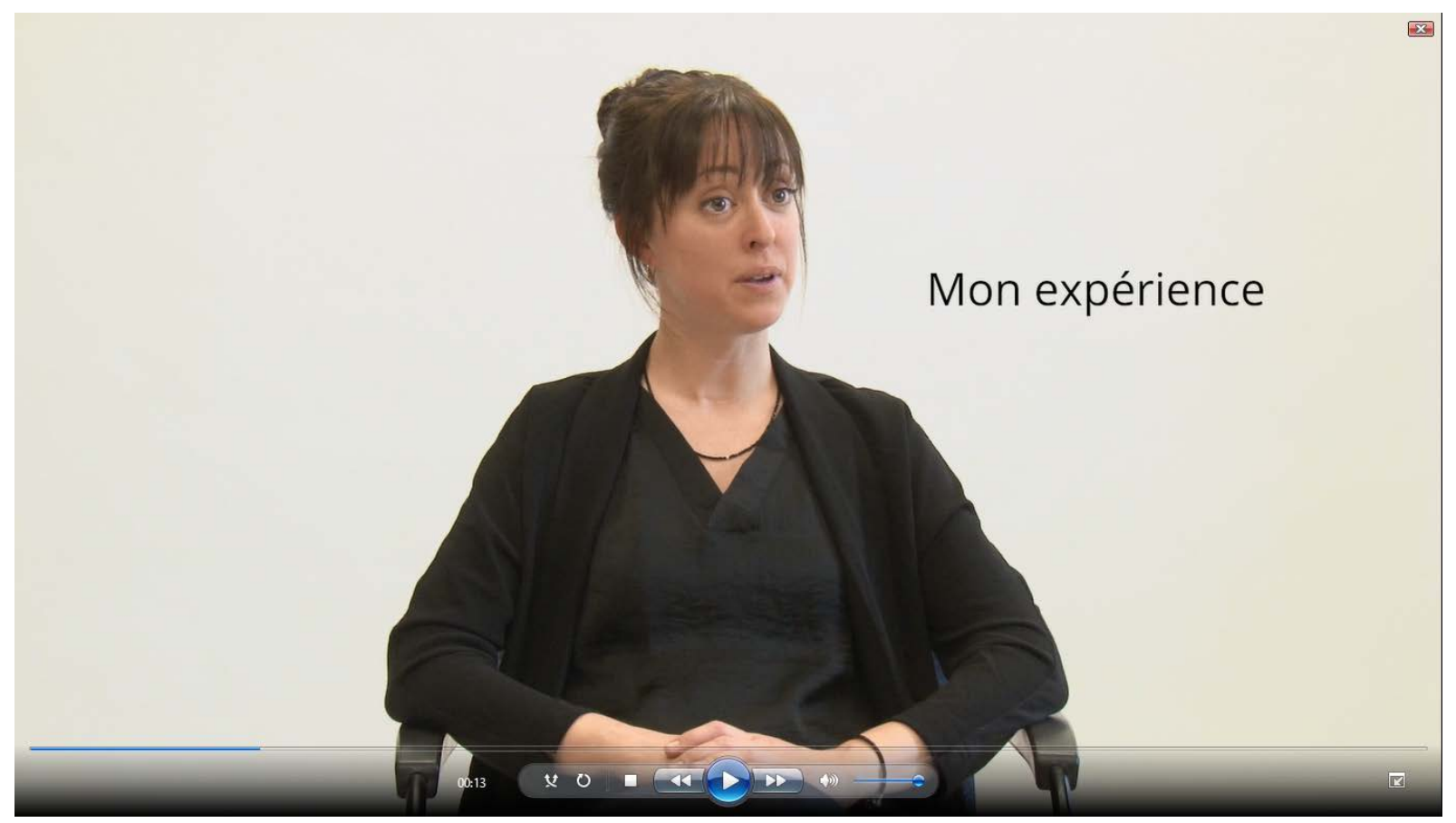

(a) Without disability

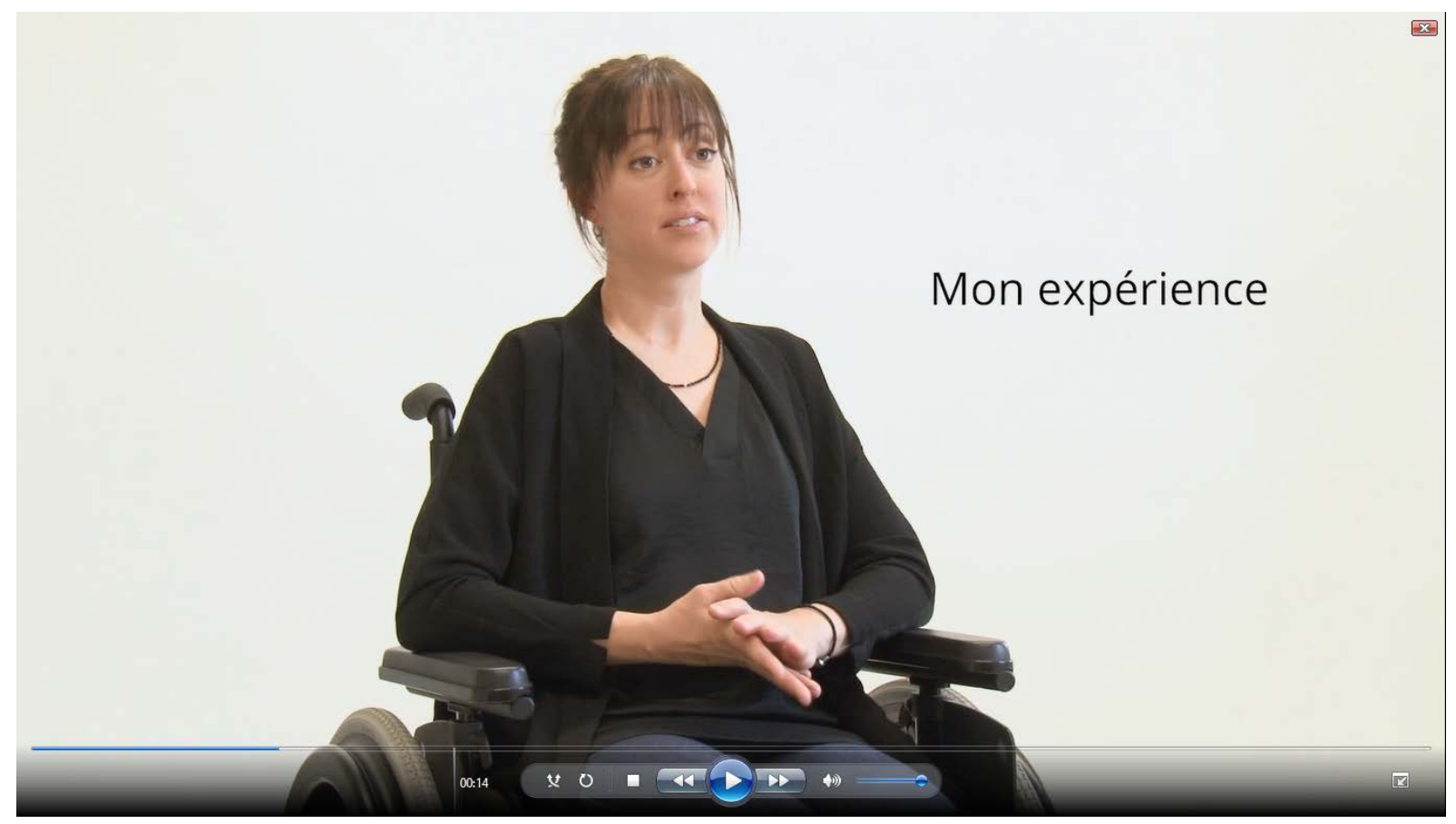

(b) With disability

Figure 5: Video resume. Wide frame 


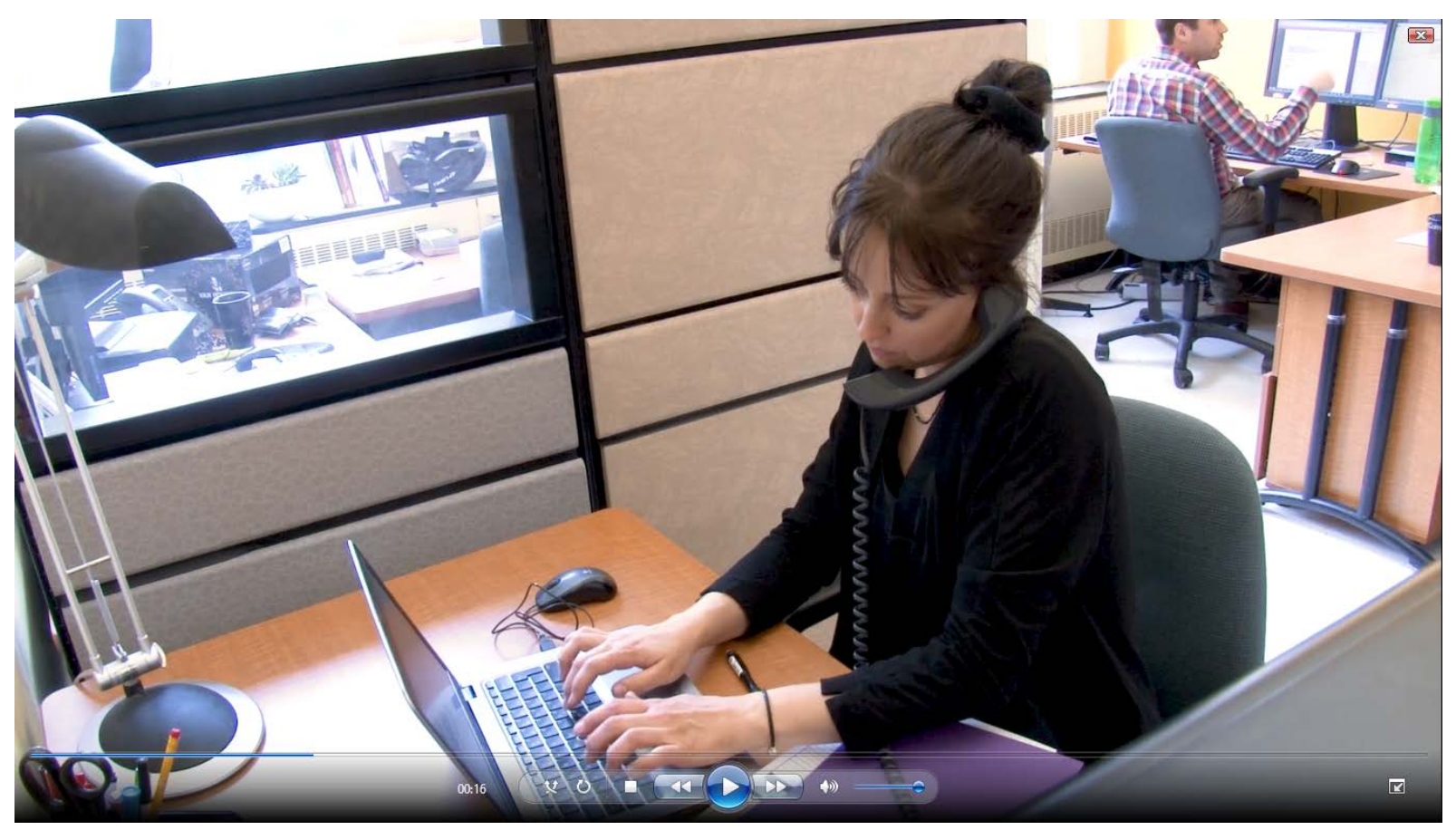

(a) Without disability

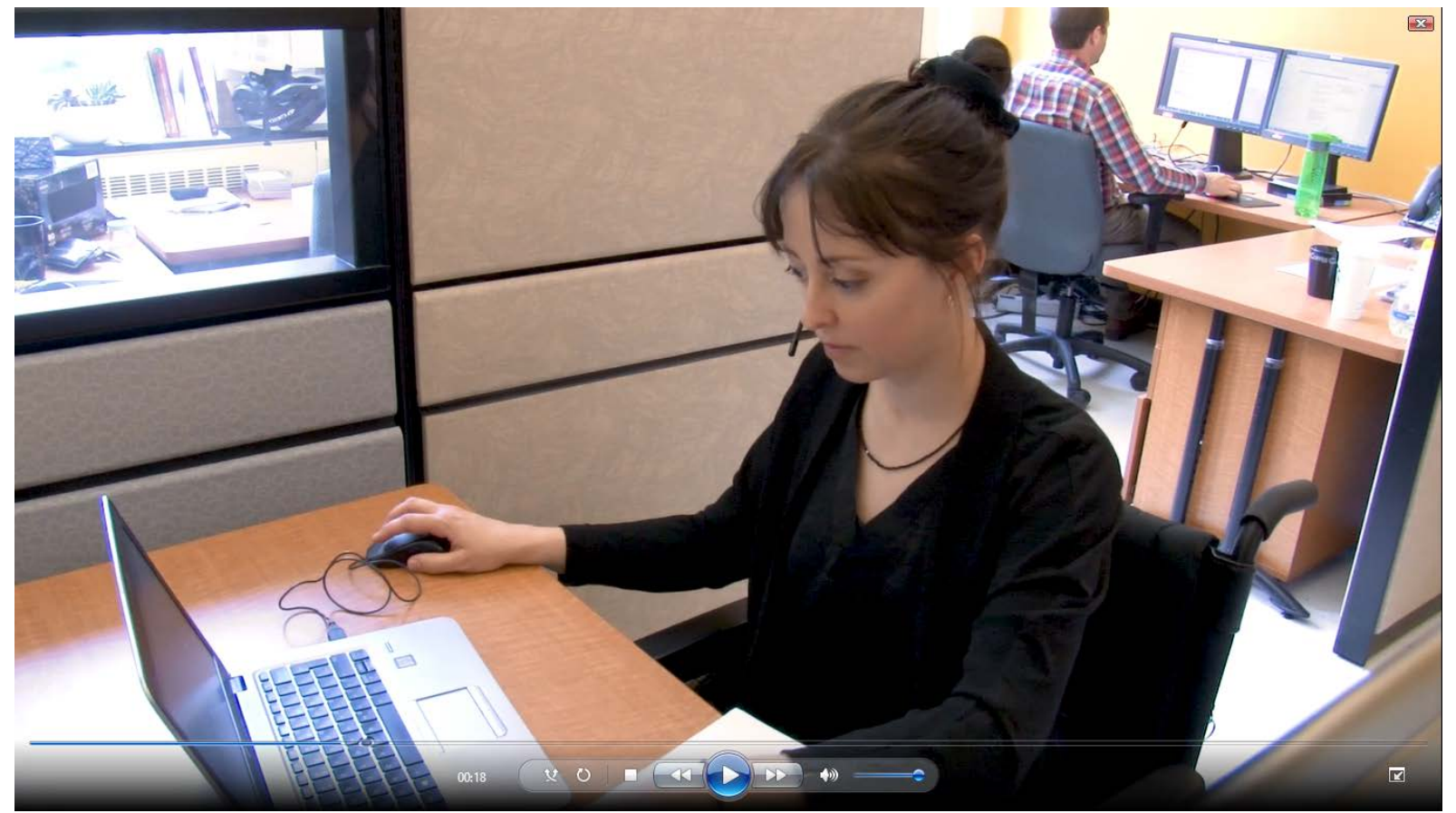

(b) With disability

Figure 6: Video resume. Office take 


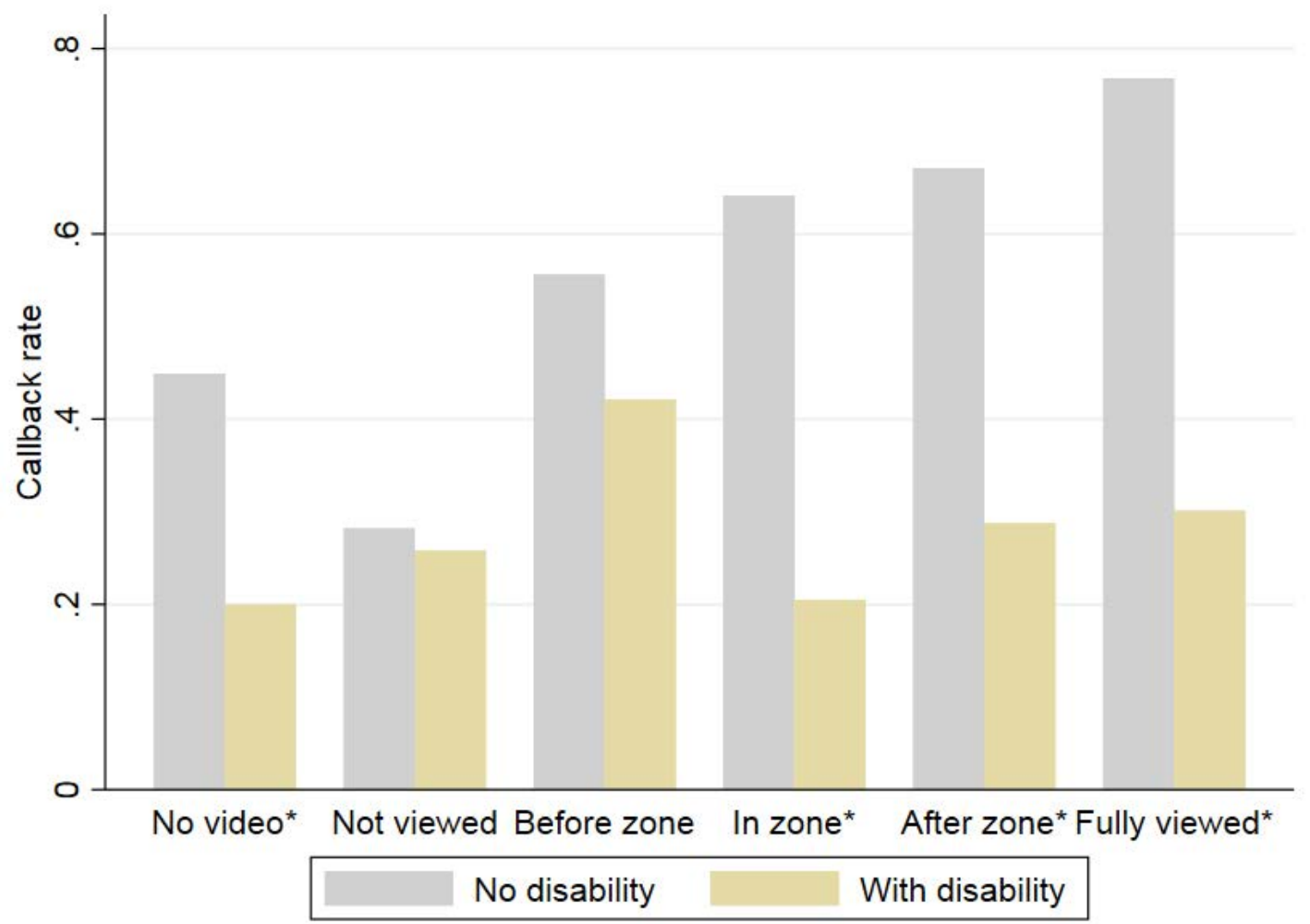

Figure 7: Callback rates and viewing categories for firms who received an invitation to view a video resume. Category "Not viewed" captures firms that did not view their videos. Category "Before zone" contains firms that stopped viewing before the revelation zone. Category "In zone" contains firms that stopped viewing in the revelation zone. Category "After zone" captures firms that stopped viewing after the revelation zone but before the end of the video. Category "Fully viewed" captures firms that finished viewing the videos. Callback rates for the "No video" category are computed for firms that did not receive an invitation view a video resume. ${ }^{*}$ indicates within-category significant differences in callback rates between revelation or not of a disability. 


\section{References}

Abel, M., R. Burger, AND P. Piraino (2020): "The value of reference letters: Experimental Evidence from South Africa," American Economic Journal: Applied Economics, 12, $40-71$.

ACQUisTI, A. AND C. FONG (2020): "An experiment in hiring discrimination via online social networks," Management Science, 66, 1005-1024.

Ameri, M., L. Schur, M. Adya, F. S. Bentley, P. McKay, And D. Kruse (2018): “The Disability Employment Puzzle: A Field Experiment on Employer Hiring Behavior," ILR Review, 71, 329-364.

BAERT, S. (2016): "Wage subsidies and hiring chances for the disabled: some causal evidence," The European Journal of Health Economics, 17, 71-86.

Behaghel, L., B. CRépon, AND T. Le Barbanchon (2015): “Unintended effects of anonymous resumes," American Economic Journal: Applied Economics, 7, 1-27.

Bellemare, C., L. Bissonnette, AND S. KRÖGer (2016): "Simulating power of economic experiments: the powerBBK package," Journal of the Economic Science Association, $2,157-168$.

Bellemare, C., M. Goussé, G. Lacroix, And S. Marchand (2018): “Physical Disability and Labor Market Discrimination : Evidence from a Field Experiment," IZA DP No. 11461.

Bertrand, M. And S. Mullainathan (2004): “Are Emily and Greg more employable than Lakisha and Jamal? A field experiment on labor market discrimination," The American Economic Review, 94, 991-1013.

Bunel, M., Y. LHorty, AND P. Petit (2016): “Discrimination based on place of residence and access to employment," Urban Studies, 53, 267-286.

Cahuc, P., S. Carcillo, A. Minea, and M.-A. Valfort (2019): "When Correspondence Studies Fail to Detect Hiring Discrimination," IZA Discussion Paper No. 12653.

CARD, D., J. Kluve, AND A. Weber (2018): "What works? A meta analysis of recent active labor market program evaluations," Journal of the European Economic Association, $16,894-931$.

Crépon, B. And G. J. VAn Den Berg (2016): “Active labor market policies," Annual Review of Economics, 8, 521-546.

EvcIL, A. N. (2009): "Wheelchair accessibility to public buildings in Istanbul," Disability and Rehabilitation: Assistive Technology, 4, 76-85. 
Goldfarb, A. AND C. TUCKer (2019): "Digital Economics," Journal of Economic Literature, 57, 3-43.

Goldin, C. And C. Rouse (2000): "Orchestrating impartiality: The impact of" blind" auditions on female musicians," American economic review, 90, 715-741.

HecKman, J. J. (1998): “Detecting discrimination," Journal of Economic Perspectives, 12, 101-116.

KAUER, L. AND E. Deuchert (2017): “Hiring subsidies for people with a disability: Helping or hindering?-Evidence from a small scale social field experiment," International Labour Review, 156, 269-285.

KuHn, P. AND H. MANSOUR (2014): "Is Internet Job Search Still Ineffective?" The Economic Journal, 124, 1213-1233.

LAcroix, G., T. KAmionKa, AND L. Gilbert (2011): “The Impact of GovernmentSponsored Training Programs on the Labor Market Transitions of Disadvantaged Men," in Advances in Econometrics, ed. by M. Verbic, Rijeka: IntechOpen, chap. 4.

LAHEY, J. N. (2008): "Age, women, and hiring: an experimental study," Journal of Human Resources, 43, 30-56.

NeUmarK, D. (2012): "Detecting discrimination in audit and correspondence studies," Journal of Human Resources, 47, 1128-1157.

NeUmark, D., R. J. BANK, AND K. D. VAN NORT (1996): “Sex discrimination in restaurant hiring: An audit study," The Quarterly Journal of Economics, 111, 915-941.

Oreopoulos, P. (2011): "Why do skilled immigrants struggle in the labor market? A field experiment with thirteen thousand resumes," American Economic Journal: Economic Policy, 3, 148-171.

PAtAcChini, E., G. Ragusa, AND Y. ZenOU (2015): “Unexplored dimensions of discrimination in Europe: homosexuality and physical appearance," Journal of Population Economics, 28, 1045-1073.

PhILliPS, D. C. (2019): “Do Comparisons of Fictional Applicants Measure Discrimination When Search Externalities are Present? Evidence from Existing Experiments," The Economic Journal.

RAVAUD, J.-F., B. MADIOT, AND I. VILle (1992): “Discrimination towards disabled people seeking employment," Social Science \& Medicine, 35, 951-958.

RоoтH, D.-O. (2009): “Obesity, attractiveness, and differential treatment in hiring a field experiment," Journal of Human Resources, 44, 710-735. 
Siegelman, P. AND J. HeCKMAN (1993): “The Urban Institute audit studies: Their methods and findings," Clear and Convincing Evidence: Measurement of Discrimination in America, Washington, 187, 258.

Stanton, C. T. And C. Thomas (2015): “Landing the First Job: The Value of Intermediaries in Online Hiring," The Review of Economic Studies, 83, 810-854.

Thapar, N., G. Warner, M.-L. Drainoni, S. R. Williams, H. Ditchfield, J. WierBICKY, AND S. NESATHURAI (2004): "A pilot study of functional access to public buildings and facilities for persons with impairments," Disability and Rehabilitation, 26, 280289. 